\title{
Adolfo Celi, um olhar para dois mundos*
}

"O ensaio foi publicado em italiano em suplemento monográfico da revista Lumière, n.29, jan-março 2002, com titulo Celi regista: un teatro tra vecchio e nuovo mondo. Apoio do CNPq.

Alessandra VannuCCI

Pontificia Universidade Católica do Rio de Janeiro/PUC - doutoranda 


\section{Resumo}

O ensaio resgata a vivência brasileira de Adolfo Celi, ator e diretor italiano ativo em cinema e teatro (1922-1986), inserido no laboratório paulista da renovação, ná década de 1950. Sua atuação impôs, no palco, o legado texto-cêntrico de Silvio d'Amico e a utopia do ator plástico de Copeau e, na tela, a estética neo-realista associada a uma atuação fortemente narcada pelo ideário teatral moderno. As intuições, a herança, as oportunidades e as invenções perdidas desta experiência transcultural sugerem um quadro de realização somente parcial do projeto modernizador: Ao entrar na década de 60 , é a sensação de ter esgotado um ciclo existencial que fornece a Celi um válido álibi para o retorno. Álibi (1969), seu terceiro e último filme como diretor, realizado na Itália com Gassmann e Lucignani, é um testemunho de vida e memórias, de raiva e de saudade do Brasil: e um precioso guia para entender sua extraordinária 'aventura americana'.

\section{Palavras-chave}

Adolfo Celi, teatro, cinema

\section{Abstract}

This research is about the extraordinary Brazilian experience of Adolfo Celi, italian actor and director of theatre and cinema (1922-86). In São Paulo he directed the TBC (Teatro Brasileiro de Comédia) in which inserted ideas from italian performing reform (text-priority, composed interpretation) and cinematographic aesthetic (neorealism). His presence, as an italian of the reconstructing generation, in this euphoric period of Brazilian development, while the show business is beginning with simultaneous modern theatre, cinema, museums and television being projected for a mass public, suggests a transfer of ideas just partially realized. Alibi, his last film as a director (Italy 1969), with Gassmann e Lucignani, is a precious guide to understand this extraordinary migration of an italian, this alternative 'american adventure'.

\section{Key words}

Adolfo Celi, theatre. cinema 
A dolfo Celi, esse siciliano de olhos claros num rosto grande e imperioso, amadurece sua arte na intensa trama de amizades, provocações e afinidades promovida, na geração, por Silvio d'Amico e seu apostolado em favor da renovação teatral realista. Aos 19 anos, em 4l, Celi é matriculado (como aluno ator, logo transferido para o curso de direção) na Accademia d'Arte Drammatica de Roma, onde então a direção cênica, resgatando-se de seu surgimento em odor de fascismo, configurava-se como arte poética e oficio de resistência aos carácteres falsificadores a ela atribuídos pelo Regime. A intensa troca consentida por algumas vigorosas amizades (como a que liga Celi a Luigi Squarzina, Luciano Salce e principalmente a Vittorio Gassmann) anima peculiares contrapercursos pedagógicos rumo ao estranhamento, praticado pelo viés de rituais exclusivos no esotérico Grupo dos 11 . Em Educação teatral, diário do grupo, eis como Gassmann e Salce descrevem o jovem Celi: "Adolfo tinha ombros quadrados e olhos cinza, metálicos. Isto nos iludiu por algum tempo: o julgamos um 'positivo'. No entanto, talvez por ter nascido em 22 , ele aninhava igualmente milimétricos problemas de formação espiritual; incerto e tímido a seu modo, também procurava soluções e as pretendia, genericamente, da vida. O colóquio era o que, de fato, lhe fornecia a chave necessária. Em sua essência, Adolfo era um cara 'transparente'; chegava-se com ele a uma rarefeita lucidez de impressões, sabores e cheiros. Daquela nossa primeira turma de direção na Accademia, ele era o único que sabia dar umá fala com autêntica precisão (tocava violão, de ouvido)". E termina "Éramos 11, todos de 22, nenhum pederasta"' .

1. Inédito, o diário é conservado no arquivo particular de Leonardo e Alessandra Celi, em Roma. 


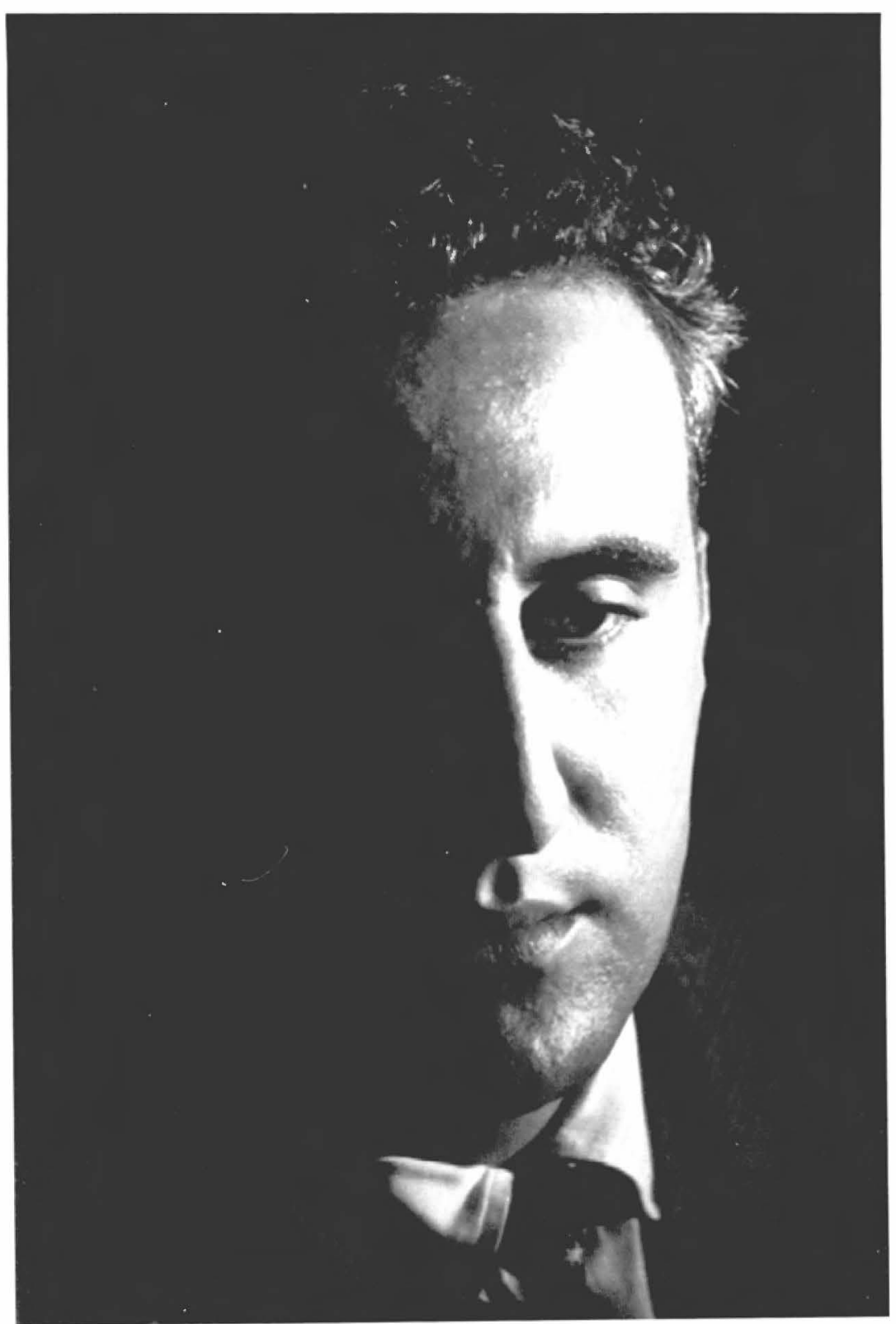

\section{Adolfo Celli}

Fotógrafo não identificado/ CEDOC Acervo FUNARTE 
Dessa que se vem configurando como a 'geração dos diretores' (Meldolesi, 1984) Celi separa-se uma primeira vez, quando é chamado para o exército, em dezembro de 42. Sua opção de solidão, acompanhada por uma carta de adeus em que denuncia as síndromes exibicionistas do grupo, atinge as frágeis compensações dos amigos (Squarzina, Gassmann e Salce) os quais, no entanto, ainda preferem a extensão perpétua da experiência acadêmica em busca da sempre perfectível 'cena dirigida'. Após o diploma e já liberado do Exército, em 46, Celi ingressa sozinho no mercado, estreando em Milão, com uma companhia profissional (De SicaBesozzi-Gioi), um espetáculo bem-sucedido (Times of your life, de William Saroyan), destinado a tornar-se seu cartão de visita quando de sua chegada ao Brasil. O compromisso do grupo devia parecerlhe por demais vinculador numa década em que tudo estava para acontecer; enquanto os grandes atores, donos dos palcos, mas ainda dependentes do repertório pré-bélico, se mostravam disponíveis ao render da guarda e abriam espaço para o fervor diretivo dos jovens. Enfim, evidentemente convencido das vantagens da solidão, Celi separa-se do grupo mais uma vez ao viajar com Aldo Fabrizi para a Argentina, onde atuaria no filme Emigrantes. Era 1947: voltou para a Itália em 1964.

Apesar dessas reiteradas despedidas, a extraordinária aventura de Celi, que - deixando-se seduzir pelo fervilhar de propostas teatrais e cinematográficas entre Buenos Aires, São Paulo e Rio de Janeiro, e ignorando os apelos dos amigos - acaba por ser conquistado pela América, revela sempre a saudade daquela geração movida pelo projeto de implante da direção e expressa o anseio de perpetuar aquele projeto geracional, tornando-o uma missão pedagógica, reproduzindo o clima dos primeiros tempos naqueles países, onde tudo ainda estava por fazer.

\section{A sensação da América}

A narração da viagem esgota-se na aturdida percepção da distância; essa, enquanto medida geográfica e dos anos que o separam da Itália, é negada pela generosa coerência existencial das oca- 
siões oferecidas pelo Novo Mundo. Em Buenos Aires, em 46, Celi realiza (numa Antígona montada com um grupo jovem) as mais ousadas sugestões experimentais de Orazio Costa, mestre de direção da Accademia - declinando as amplas possibilidades da palavra dita 'por dentro', como "ressonância do inconsciente" (Celi, in Rabetti, 1989, p. 342). Logo em seguida surpreende-o o convite, chegado misteriosamente por carta, do recém-fundado Teatro Brasileiro de Comédia - o que faz com que em janeiro de 49, aos 27 anos, convalescente de uma operação na garganta e atemorizado pelas oito horas de vôo, ele embarque para São Paulo num velho DC8. Era a primeira vez que viajava de avião. Pousa às três da tarde; às cinco está montando as luzes do espetáculo que estréia às oito - Ingenuidade, de Van Druten, direção de Madalena Nicol. Peça "montada ingenuamente, mas com sinceridade", anota Celi, que lembra ainda: "Eu vinha contando as minhas experiências, os defeitos deles; explicando aquela que, para mim, era a estrada certa. Observava-os atentos e interessados beberem as minhas palavras como ouro puro, madrugada adentro, sem dar sinal de cansaço. Eu era diplomado na Accademia de Roma: isso para eles era sinal de competência, preparação técnica e artística indispensáveis". ${ }^{2}$ Nada consta a Celi sobre o teatro brasileiro, enquanto em Buenos Aires prosperavam então 40 companhias profissionais; e o impacto com a língua portuguesa, que ignora, desnorteia-o. Contudo, atraiem-no a virgindade daquele palco 'vazio', em que o trabalho estava em fase germinal, a percepção eufórica de grandes possibilidades abertas para uma pioneira conquista, que fazia com que, naqueles anos em São Paulo, "advogados e médicos ${ }^{3}$ abandonassem suas profissões para tornar-se atores" (Celi, in Rabetti, 1989, p. 356). É a "sensação da América... a que no Brasil se traduz com a frase plantando, dá" (ibidem, p. 353).

A modernidade biográfica de Celi, assim como dos outros diretores que ele mesmo convoca até o final de 1950 (Ruggero Jacobbi do Rio de Janeiro, onde trabalhava como diretor desde 1947,

2. Celi, in A volta, roteiro do filme Álibi.

3. Como Paulo Autran (advogado), Valdemar Wei e Sergio Brito (médicos). 
Luciano Salce e 'Flem' Bollini de Roma), resolve o desconcerto inicial de emigrantes, viabilizando uma enérgica refundação local da missão reformadora. Quando não se reconhece, convenciona-se entre o país de origem e o Brasil um paralelo, por vezes incôngruo aos pressupostos históricos, lá onde o desenraizamento de significados inadequados ao novo contexto mostrava-se necessário, antes à superação da tragédia humana da guerra, depois a um mergulho no exótico que propiciasse o pleno sabor de 'descoberta'. Por um lado, a impaciência desses jovens diretores diante da paralisia em que ingressava então o mercado italiano, em fase de especialização sistemática ("a sensação de que a aventura da direção tivesse se esgotado”, como capta Meldolesi, 1984, p. 219); por outro lado, o pressentimento de poder ser, mudadas as latitudes, não só continuadores de um saber, mas também criadores de novas linguagens justifica a percepção não penosa da emigração, mas, sim, como um 'feliz destino' (dirá Jacobbi). Essa atitude positiva favorece o surgimento de oportunidades, a formulação de objetivos coerentes com suas ambições projetivas e, com frequência, a plena realização de tais programas, justificando o desenraizamento como profícua refundação. Mata-se a saudade dos sonhos juvenis no 'grupo' da Accademia (embora parcialmente confortados pela concentração em São Paulo de parte representativa da geração ${ }^{4}$ ) com sofridas evocações daquele tempo ofuscado pelas bombas, que cumpriria agora suas promessas num Brasil ensolarado e cordial, conotado como espaço 'outro' (em que os sonhos se tornam reais) e 'novo' (virgem de significações e aberto a todas elas). Assim, os alegres fogos de São João distraem Celi da severa memória de outras explosões (enquanto ensaia Otelo com os alunos da Escola de Arte Dramática, no mezanino do teatro, assim como o ensaiava na Accademia sob os bombardeios); assim, Salce jubila ao deparar-se, recém-chegado naquele palco longínquo,

4. Chegam ainda, em 49, o roteirista Fabio Carpi e os cenógrafos Tulio Costa, Bassano Vaccarini e Mauro Francini; em 54, os diretores Gianni Ratto, Alberto d'Aversa e, por breve tempo, Dino Risi - para citar apenas os mais conhecidos. Por pouco até Vittorio Gassmann não se lança na aventura brasileira, à qual prefere Hollywood, desfazendo acordo anterior com TBC-Vera Cruz (Revista Manchete, n. 18, 23/8/1952). 
com o mesmo Fils d'Eduard que deixara em Roma - como se nunca tivesse partido de lá ou "como se um milagre tivesse acontecido aqui, os milhares de quilômetros que eu acabava de percorrer desaparecidos e um fio mágico [tivesse] unido os palcos de um continente ao outro". 5 Para ocasião da faustosa estréia de Nick bar no TBC, Jacobbi evoca a humanidade dolente da Milão invernal, em que se confundia um Celi aflito por outros times of life (trata-se do mesmo texto de Saroyan com que Celi havia estreado em 46 no circuito profissional italiano): "uma canção de misérias e gloriosas esperanças do homem; canção de gente pobre, como nós éramos, de gente que vivia em bares e botequins, como nós vivíamos, à sombra de duas guerras, como nós estávamos e estamos". Gente angustiada, para quem a América não poderia ser senão sonho de um mundo 'outro', suavemente promissor e sem conflitos: "Passaram os dias, veio a estréia e o sucesso: o mais belo sucesso do teatro italiano daquele ano. Depois da estréia fomos a uma boite. Adolfo sentou num canto, bebendo e pensando; parecia triste. A orquestra tocava - juro! - Aquarela do Brasil'. ${ }^{6}$

Enfim, a 'sensação da América' a que Celi apela, talvez em nome da geração, é a desejada imagem de um mundo diverso e melhor. Para Celi, contudo, o caminho rumo a esse mundo não é político. Ao contrário: pela arte, evade do sectarismo do real dilacerado pelas reivindicações de frente, classe ou partido e procura no palco um espaço autônomo e superior em que seja possível perpetuar a fundação da realidade em sua mais pura dimensão poética.

Entre quatro paredes

O verdadeiro realismo é o do teatro e não o da vida. Na vida o realismo se apresenta, ninguém ousa negá-lo, com os maiores defeitos. No teatro, os defeitos são corrigidos e o realismo se apresenta artisticamente. Isto quer dizer que o teatro corrige a vida; portanto, a vida está realmente no palco e não na vida. ${ }^{7}$

5. Salce, programa de Os filhos de Eduardo, de M-G. Sauvaujon. TBC-SP, 1951.

6. Jacobbi, 'O bar da esquina', no programa de Nick Bar (Times of your life) de W. Saroyan. TBC-SP 1949.

7. Celi, apresentação à imprensa de Nick bar e da primeira temporada do TBC. Diário de São Paulo, 6/2/1949. 
Nos primeiros programas do Teatro Brasileiro de Comédia (TBC) de São Paulo, fotografias e textos de diretores, atores e mestres modernos veiculam o esforço de designar uma ideologia programática, que se alastra das mais sofisticadas elucidações teóricas aos mínimos detalhes de cenotécnica, justapondo modernidade e métier no intuito de dispensar ao público noções de 'bom teatro'. Em composição eclética, alternam-se frases de Copeau, Dullin, d'Amico ou Jouvet com o testemunho do maquinista e da camareira do $\mathrm{TBC}$; às finíssimas notas críticas de Jacobbi segue a transcrição de velhos manuais operativos sobre maquilagem ou iluminação. Tais justaposições revelam uma cultura em formação entre projeto vanguardista e prática possível, a qual se apóia - orgulhosamente pioneira - em seus feitos anteriores a fim de atribuir nova dignidade à arte desqualificada pela vulgarização do 'velho teatro' brasileiro. Enquanto diretor artístico estrangeiro, diplomado e carismático, Celi é propulsor de tal movimento, que intenciona requalificar o status da arte teatral, isto é, reaproximá-la do bom-gosto burguês. Disciplina à prova do profissionalismo da equipe, forma estética 'de nível internacional' e gênero dramático (em substituição à 'baixa comédia', dominante no mercado popular) são os critérios com os quais Celi se compromete publicamente para a produção de um teatro 'sério'. Entendam-se à luz dessa perspectiva moralizadora seus pedidos de 'licença' para as freqüentes 'concessões' ao infamado gosto do público médio, com que a casa deve compactuar desde sua primeira temporada para garantir-se hegemonia no mercado. Boulevards e outros gêneros 'inconsequiêntes' (isto é, dotados de comicidade demencial) são confiados a Jacobbi e Salce, cuja sensibilidade mais se inclina ao riso, enquanto Celi aplica-se com coerência aos manifestos estéticos (como o citado em abertura de parágrafo: instigando à paradoxal inversão do princípio de verossimilhança na arte que impõe à natureza 'real' do ator de adequar-se ao imperativo 'poético' do personagem) e aos laboratórios de interpretação. Esses se realizam em pleno clima experimental - 'entre quatro paredes', como, em 1950, os ensaios de Huis clos, de Sartre. Sem entrar na querelle homosexual-existencialista da peça e contudo aproveitando-se do inevitável succés de escandale, Celi faz do espetáculo o manifesto 
de sua 'cena dirigida'. Surpreende na literatura de Sartre uma imprevista e compacta teatralidade, que se formaliza em estruturas rítmicas de violência desconcertante e se organiza numa composição em nada comparável ao que havia sido apresentado àquele público até então. A poética sartreana reduzida ao essencial dos personagens 'entre quatro paredes' afirmaria, segundo Celi, a responsabilidade absoluta da 'diversidade' individual contra o conformismo classificatório de qualquer instituição. Volta a manifestar-se, nessa fase, como ideologia individualista adequada ao personalismo anarcóide dominante na caótica sociedade brasileira, sua intolerância ao sistema/grupo que apaga as margens sensíveis de um caráter peculiar como o de Celi - cujo máximo desconforto, uma angústia bem pirandelliana, poderia ser "o conflito que um ser humano trava consigo e com aqueles que o circundam, quando se dá conta de não poder mais suportar a sua condição inerte e casual dentro de uma coletividade" $"$.

O teatro, virilmente ocupado pelo diretor - ao qual cabe suscitar no público, mediante a presença em cena dos atores, a consciência do nexo emoção/ilusão/realidade estabelecido pela arte -, é lugar super-humanizador de 'discussão pública'9 em que é possível, ao mesmo tempo, transformar a dialética da incompreensão humana em poesia. A descoberta da palavra em sua essencial simplicidade (não poluída pela mutável emoção do interprete, mas emergida como ritmo primordial do subconsciente e, assim, feita veículo de uma realidade poética franqueada à impureza do real) instiga a pesquisa cênica de Celi desde o encontro com Saroyan, em cujo "lirismo crepuscular"10 o diretor reconhecia indícios de um realismo poético comparável àquele então perseguido pelo neo-realismo cinematográfico romano. Recusando-se a lançar mão do verossímil, a 'cena dirigida' por Celi foge às determinações funcionais do realismo

8. Escreve em 1960, no programa de Geração em revolta, Teatro Copacabana-RJ. A afirmação pessoal é leit-motiv de Celi; a renúncia a ela, diante dos anseios de autoria coletiva expressos pela nova geração, esgota sua missāo brasileira.

9. Celi, 1951, programa de Seis personagens à procura de um autor, de Pirandello, TBC-SP.

10. Celi, 1949, programa de Nick bar, cit. TBC-SP. 
cotidiano, pois trata de estipular uma dimensão autônoma de teatroarte, além do real, e não de teatro como imitação da vida. O caminho dessa busca comporta, segundo Celi, a aplicação de um realismo radical enquadrado por rígido projeto formal que, 'suspendendo' o ator em cena com ênfase icástica, produziria uma visão alegórica, um artefato de realidade puramente ilusório e livre de clichés miméticos. Esse 'novo' realismo (sugerido pelo encontro da 'geração dos diretores' com o novo realismo americano de Saroyan, Maxwell Anderson, Tennessee Williams) pode tornar-se meio de conhecimento, enquanto experiência visual-sonora capaz de perturbar a óbvia gramática dos nexos sensíveis, própria do realismo tradicional. A verificar sua dimensão poética em cena intervêm critérios interpretativos que remetem ao apostolado acadêmico de Silvio d'Amico, como a validade universal do texto (que oculta uma verdade 'sua') e a unidade originária do gênero dramático (que se representa como sucessão absoluta de ações no tempo presente, sem distância épica nem narrador). Para o magistério do diretor que, servo do texto e senhor da cena, interpreta aquela verdade e orquestra aquela sucessão, é necessário um "material plástico" - o ator, conforme sua célebre definição juvenil ${ }^{11}$-, cujo corpo (sua acentuação mímico-fonético-interpretativa) se encaixe no corpo total da visão espetacular concebida e montada pela direção. Desmontadas as pretensões de verdade da expressão espontânea, cabe ao diretor perfurar as camadas fisiognômicas/significantes do intérprete, intervindo com diversos fatores associativos e de 'angulação' como 'aspas' que requerem do ator certa "irresponsabilidade criativa" (ibidem).

O uso do ator, associado a outros elementos plásticos em sequiencias espaço-temporais que se formulam a partir das possibilidades criativas do observador externo é, para Celi, evidente no caso cinematográfico, em que o olho externo se concretiza na câmera, e o processo criativo dilata suas possibilidades para a fase de montagem. Enquanto no palco a simultaneidade dos processos de expressão/recepção limita a proliferação de signos à presença expressiva

11. Celi no artigo juvenil 'L'attore come materiale plastico', in Roma fascista, XXI, 20/5/1943. 
do ator e aos resultados de sua reflexão sobre o sentimento expresso, a sugestão de uma cena filmada pode ter sido gerada a posteriori, sem que o ator tenha jamais tido intenção ou consciência de estar expressando tal sentimento. A marcante organização simbólica por seqüências espaço-temporais encadeadas por signos recorrentes, no filme Caiçara (dirigido por Celi em 51, para estréia da Vera Cruz), indica manipulação proposital, embora empírica, da narração realista intencionando potencializar e totalizar a dimensão alegórica e poética. A história do desaventurado casamento da órfã com um pescador, originando a explosão e extinção dos males endêmicos de um povo predestinado, permite delimitar o desenvolvimento dos conflitos aos confins naturais da ilha e, assim, dignificar os comparsas (os fadados caiçaras) como inquietantes observadores do drama dos personagens (um coro grego, anota Galvão, 1981: 233-255). A montagem, concebida como elaboração geométrica e composição de detalhes em rígidos quadros expressivos, acentua essa tendência ao isolamento, fazendo da ilha uma metáfora orgânica e totalizante da nação - segundo a qual o Brasil (antigo) da irracionalidade ritual, expressa nas mandingas da preta velha, seria assimilado pelo Brasil (moderno) da racionalidade e do trabalho, possibilitando a eliminação do mal no caminho reto do progresso liderado por uma burguesia consequiente e positiva. A imagem do Brasil enquadrada nesse modelo (que se diria griffithiano ou neo-realista) resulta especialmente a posteriori, em virtude da composição imagética e formal de elementos plásticos (objetos, corpos, olhares) em movimento num espaço fechado. O próprio isolamento (a distância do cotidiano) revela, contudo, ser categoria criativa necessária ao experimentalismo de Celi rumo a um realismo 'puro', na medida em que - por instância do diretor - o elenco passa, incomunicável, todo o período da filmagem na Ilha Bela.

Preconizado por Celi como projeto estético desde 1949, o realismo 'puro' viabilizado pela cena dirigida realiza-se empiricamente, seja na produção teatral e na cinematográfica, como busca 'entre quatro paredes' de uma linguagem atorial que verificava então sua radical ruptura com o idioma tradicional dos palcos brasileiros, que pisavam então grandes atores sem concorrência (nem 
nas telas) para seus excessos líricos, seu histrionismo e sua presença convulsa, de herança romântica. Um 'velho estilo' que se diria “muito menos exótico do que démodê" (Lévi-Strauss, 1999:97, ao descrever a cena pública), ao qual Celi opõe sua premeditada recusa ${ }^{12}$ em nome da utopia minimalista do comédien desincarné, cultivada por sua geração e por ele inoculada na geração de atores que protagonizam os primórdios do TBC e da Vera Cruz. De acordo com essa disciplina, o ator busca o papel fora de si, não 'imitando' nem 'compondo', mas, sim, emprestando seu corpo para 'encarnar' o personagem, penetrando-o pelos mínimos detalhes até ser dominado/ dominar sua realidade ilusória num estado semiconsciente que (conforme Dullin ${ }^{13}$ ) “emana da alma, irradia e se impõe”. É a "presença', mítico graal da arte moderna do ator.

Senão, vejamos. Paulo Autran recorda sua angustiada busca do Rei Creontes (na Antígona, de Sófocles-Anhouil, em 52, seu terceiro trabalho no TBC) como um processo de perda de segurança diante da instância de Celi de minimizar os signos expressivos ${ }^{14}$ até chegar ao "estalo" que o franqueia de seu corpo e voz, livra-o das inflexões ordinárias (espontâneas) que tolhiam o personagem e lhe permite a conquista da senhoria (artificial) sobre as palavras. Nessa busca rumo à superação do realismo, a partir do realismo, Stanislavski revela-se guia essencial. Tal endereço de pesquisa, anos mais tarde indicado por Celi citando o 'método' aplicado pelo Actor's Studio na interpretação cinematográfica ${ }^{15}$, na época de sua direção no TBC apóia-se, contudo, em métodos ecléticos e empíricos de medição, caso a caso, das dificuldades do ator, cujo objetivo nos ensaios dirigidos é conquistar a 'presença' em cena de corpo inteiro, ao vivo e

12. "A maneira de representar no Brasil, naquela época, parecia-me extremamente caraterística de uma descendência portuguesa de velho teatro e correspondia a uma velha maneira de representar na Itália [...] Eu queria acabar com aquilo." Celi, entrevista a G.Lerner in Fernandes \& Vargas, 1983, p. 124

13. No programa de Nick bar, cit.

14. "Celi não queria uma composiçāo de velhinho. Queria que eu passasse a autoridade, o peso do rei, seu desencanto com a vida, seu ceticismo, com sutilezas de interpretação apenas. Eu entendia e concordava. Mas nos ensaios via que ele nāo estava satisfeito. E repetia, repetia, repetia, e ele explicava, explicava, explicava...", in Guzik, 1998, p. 68.

15. "Acho que nós chegamos antes", comenta Celi, in Fernandes \& Vargas, 1983: 124. 
quase sem intervalos. ${ }^{16}$ Os testemunhos sobre o trabalho de ensaio dirigido por Celi se contradizem: por um lado, Cleyde Yaconis, atriz então estreiante, evoca-o instruindo-a com exercícios de memória emotiva, resgatando as recordações da avó para descobrir "quais elementos de velha eu dava: atravessar a rua, quase ser atropelada, ver cachorro, ver criança, ver vitrine, rezar, ir à igreja; nós fomos selecionando" (Depoimentos, VI: 32). Outros o lembram concentrado em violentar os bloqueios do ator com obstáculos físicos: ao Gustavo Nonnemberg, que engrolava, Celi segurava com um lenço a ponta da língua; para conseguir o frenesi da entrada em cena do Sr. Ponza em Assimé se lhe parece, mandou Paulo Autran dar a volta ao edifício correndo; aos intérpretes de Caiçara abraçava os pés para que não balançassem o corpo e acionassem só os múscolos estritamente necessários, etc. Elisabeth Henreid afirma que Celi "falava um pouco por metáforas [...] dava as dicas, mas você tinha que desenvolver" (Dionysos, 25: 157); conforme depoimento discordante de Jacqueline Lawrence, Celi "impunha uma forma de ser e não conduzia" (in Lopes \& Saadi, entrevista 2.6.81). O próprio diretor admite ter abusado, sim (impostando os intérpretes, sugerindo as inflexões), da autoridade conferida, desde os tempos da Accademia, pelo fato de "saber dar uma fala com precisão"17. Por outro lado, aposta que, "somente porque trabalhei dessa forma, consegui certos resultados" (in Fernandes \& Vargas, 1983: 121) de atores amadores desafiados por estréias bimestrais e, logo depois, pela atolada agenda de filmagens da Vera Cruz, onde, no entanto, Celi não libera os interpretes do mesmo cuidadoso processo de construção da personagem. "Eu", continua Celi, "dava um projeto de corpo para o corpo dos atores, com a voz deles, com suas inflexões [...] dava esboços de materiais, para o ator usar: material fonético, de contraste, de inflexões, material de violência; e sugestões de gritos, choros, risadas [...] Então, eu não impunha uma marcação: impunha uma violência, uma violência fonética, uma sensação de violência. Eu gos-

16. Diverso o caso do ator cinematográfico, como anota Celi, in 'L'attore come materiale plastico', op. cit.

17. Conforme os colegas Gassmann e Squarzina, in L'educazione teatrale, op. cit. 
tava de desnortear o ator no contraste de uma sensação após a outra. $\mathrm{E}$ os atores [do TBC] reagiam muito bem a isso. Acho que eles mudaram em suas carreiras pessoais exatamente por causa desta forma de dirigir: um ritmo, uma velocidade de representar. Pois eu, na época, estava obcecado pela maneira de representar brasileira, que dava o tempo ao público para ouvir até se cansar [...] Queria passar por cima de tudo isso e dar muito mais coisas ao mesmo tempo. Todas as minhas peças duravam 10 minutos a menos do que deveriam. Eram muito mais rápidas, eram terrivelmente rápidas. Mas o público pegava." (ibidem: 125 e 122).

O método da irrupção violenta faz a passagem, portanto, de estratagema criativo (desnortear o ator) para preocupação estética (diante do risco de aborrecer a platéia), enfim para motivo de grandes êxitos comerciais. Assim, o eventual bloqueio do ator torna-se eixo da pesquisa estética e acaba gerando cenas de elevada tensão teatral: é o caso do citado sucesso de Entre quatro paredes, de 50, em que Celi consegue passar aquelas 'patologias filosóficas' ao público agredido "não com golpes de efeitos, mas com violências humanas" (Celi, in Rabetti, 1989: 368). ${ }^{18}$ Ou do memorável final dos Seis personagens, em 51, ocupado pela longa risada forçada-aponta Celi - de Cacilda Becker. A atriz não conseguia rir com naturalidade em cena, "mas tanto fez, que conseguiu inventar uma risada sua, com a qual devia descer do palco com um fôlego que, na realidade, ela não tinha. A cena então era: ela devia, rindo, atravessar o palco, a platéia e sair pela porta do fundo do teatro. Ela conseguiu. Dava arrepios..." (in Fernandes \& Vargas, 1983: 120). O trabalho do ator, no objetivo do neo-realismo poético pretendido por Celi, consistiria numa síntese expressiva entre seus meios (ou deficiências) e a idealização sugerida pelo texto: o 'equilíbrio perpétuo' entre impulso e racionalidade, naturalidade e controle, já expresso por Copeau e Jouvet (na esteira da vanguarda classicista da Nouvelle Révue

18. Já que o problema para Sartre - reflete Celi (in Fernandes \& Vargas, 1983: 129) - não era "de impor o vício lésbico, era o problema de impor uma maneira de pensar, defender um ponto de vista existencial [...] e Cacilda conseguiu ter un domínio extraordinário sobre a maneira de se impor, com aquela avidez e aquela força interior" - uma força muito além de seu pequeno e frágil corpo de atriz. 
Française). Os ensaios até alta madrugada, a troca de papéis, o contínuo retornar à mesa, a experimentação exaustiva de cada fala, de cada vírgula; as intuições no bar, diante do whisky de sempre nos remetem, afinal, à imagem de um diretor avesso aos truques e às sofisticações estilísticas e - segundo Autran - "muito mais preocupado em fazer espetáculos, em nos transformar em atores, em nos melhorar como atores, do que em nos incutir teorias na cabeça. Era comum as pessoas dizerem o Celi é uma fábrica de atores! [...] Ele formou um núcleo muito bom de atores [...] gente consciente do que é o ato de representar, do que é trasmitir um personagem à platéia" (in Dionysios, 25: 177).

\section{Objetivos para uma missão}

O esforço de 'despojar' o trabalho do ator da histrionice da velha escola, de programa geracional inspirado na batalha de Silvio d'Amico contra a degeneração (não raro por excesso de técnica) de uma arte cada vez mais pessoal que desvaira em invenções colorísticas, distraindo-se do texto, torna-se para Celi, com os anos, uma cruzada contra a improvisação: aquele jeitinho do ator nacional, que o diretor rejeita com obstinação, a ponto de escalar "o horror ao improviso" como móbil principal de sua dedicação à causa teatral brasileira. Mostrar as vantagens e "os resultados de um esforço artístico organizado", como declarará em 55 para inauguração de sua companhia com Tônia Carrero e Paulo Autran no Rio de Janeiro (in Almeida, 1987: 34); atingir o equilíbrio entre impulso criativo e cálculo (comunicativo-comercial), isto é, conquistar um saber especializado que, no entanto, 'funcione', garantindo a bilheteria; surpreender a pseudocultura erudita com uma cultura viva, agradável, emocionante, sem, contudo, dobrar-se à exploração dos mercados ou à traição do autor... Esses são os objetivos da missão profissional-moral de Celi que, como diretor $e$ diretor artístico das duas companhias em que trabalha no Brasil, se faz promotor de critérios disciplinares (respeito aos horários, equiparação dos atores, ecletismo na distribuição do repertório/papéis entre os diversos diretores e intérpretes) e garantia de valores estéticos (máxima perfeição formal, 
centralidade do texto, máxima comunicação com a platéia). A intimidade coesa, de clan ou de grande família, que, do TBC-Vera Cruz, Celi transferirá ao CTCA, é garantia da manutenção de uma mentalidade em direta ascendência nas companhias de capocomico, segundo a qual o ator não entra em cena para defender seu papel, mas o espetáculo todo" (Tônia Carrero, in Lopes \& Saadi:1980). Nunca deixando de exaltar a 'defesa' do texto (de sua poesia, vitalidade e verdade universais) como principal responsabilidade do ator moderno, Celi ao longo dos anos reitera sua idiosincrasia às degenerações do ofício, principalmente àquele 'vício perpétuo' de comentar-se, próprio à 'maneira' brasileira, que exclui o público do processo de identificação e impede-o de 'acreditar' na verdade fictícia do personagem. ${ }^{19}$

Carismático e diplomático na economia de suas amizades, Celi desde sua chegada capitaliza prestígio de leader aos olhos de colaboradores e patrocinadores, entre os quais o próprio Zampari, que amava desafiá-lo no bridge, raramente opinava acerca de suas propostas de repertório e que por ele, em 1950, se deixa convencer a investir parte ingente de seu patrimônio na produção de cinema em virtude, dizem, de uma divertida história de roubo de pérolas entre madames, filmada por Celi e Calvo em Super8 num dos badalados parties oferecidos por Zampari aos domingos em sua mansão. Surge a Vera Cruz, a babélica Hollywood paulista que, após meros quatro anos e 16 longametragens, sucumbirá a suas mastodônticas dimensões. Com distribuição insuficiente num mercado prometedor porém imaturo, Zampari e sócios bancam por três anos gastos exorbitantes de material e maquinários importados, e uma folha de pagamento contando com 80 técnicos estrangeiros, igualmente 'importados' pelo diretor-geral Alberto Cavalcanti. Celi faz a tempo dois filmes (o citado Caiçara e Tico-tico no fubá, biografia musicada de Zequinha de Abreu). Ambos com histórico polêmico, marcado por orçamento estourado e lançamento ambicioso, se por um lado garantem seu imediato êxito comercial, por outro envolvem o diretor

19. Celi, 'Estilo do ator nacional', conferência comentada por Henrique Oscar, Diário das Notícias, 29 e 30/12/1955. 
no furacão que segue a falência da empreitada. Para piorar o teor da polêmica, impondo-se então pela direita e pela esquerda, políticas protecionistas voltadas ao imperativo do desenvolvimento nacional, concentram-se contra o vistoso lobby italiano, que chega a ser acusado de arrivismo e de incompetência. ${ }^{20}$ Em plena onda de sucesso, começa para Celi uma fase de justificações e auto-crítica.

Percebendo a hegemonia italiana na renovação como movimento espontâneo, surgido a partir do sucesso de seus primeiros espetáculos em São Paulo, na origem da formação do grupo, Celi atribui o triunfo ao êxito comunicativo de sua 'vitalidade latina' (que julga compatível com sensibilidade cultural do país) e arroga-se a primazia dos resultados formais (para o que, acredita, contribuem saberes cenotécnicos e poéticos, inéditos no Brasil). De fato, a eventual ação protecionista do vínculo entre compatriotas, se houve numa primeira fase, pareceu limitada a viabilizar uma acolhida familiar aos recém-chegados e facilitar o surgimento de parcerias, não implicando a renúncia ao intuito crítico sugerido pela 'modernidade' biográfica dos italianos. Ao contrário, na dinâmica do longo período inescada pelo processo de integração individual, em que incidem as mais diversas conjunturas, eles acabam por emancipar seus destinos em função de opções pessoais estéticas e políticas - opções que justificam, por exemplo, as repentinas demissões de Jacobbi do TBC, em 52; a saída de Ratto em 54, para seguir brilhante carreira 'à parte', com o Teatro dos Sete; enfim, a que é percebida como 'defecção' de Celi, com Paulo Autran e Tônia Carrero, para fundar no Rio de Janeiro a Cia. Tônia-Celi-Autran (CTCA). O dissídio, ocultado ao público pelo positivo auspício, por parte do diretor de saída, de que "quanto mais companhias, melhor para o teatro brasileiro", 2 , aponta para uma crescente interferência de Zampari na orientação

20. Vejam as dúvidas do cronista Silvyano Cavalcanti: "No meio de tanta gente lavorando, será que alguém sabe o que está fazendo?" in Galvão, 1981: 336 . A polêmica, embora posteriormente compensada por Celi (que, em Álibi, admite irresponsabilidade ao assumir, quase inexperiente, a direção dos filmes), menosprezava a presença em São Paulo de Dino Risi e o ótimo trabalho de Fabio Carpi (roteirista) com Salce (diretor) naquele que talvez seja o melhor filme da Vera Cruz, Nas sendas do crime (1953).

21. Celi, O Estado de São Paulo, 31/8/1955. 
de repertório, especialmente no que diz respeito a seu veto a Shakespeare. Como se percebe pelas entrevistas, ${ }^{22}$ montar Shakespeare, que Zampari julgava uma ousadia cara demais, constituia, entretanto, o maior sonho de Celi, que em nome do bardo renunciaria a sua terceira direção cinematográfica. ${ }^{23} \mathrm{O}$ Otelo que estréia no Rio a nova Cia. Tônia-Celi-Autran, afinal um triunfo com suas 280 réplicas, é acompanhado no programa por uma introdução de Celi, preocupada não com a indiscutível vitalidade do texto (louvado, aliás, como um "feliz conúbio entre imanência existencial e uma perfeita forma lírica"), mas, sim, com a ausente tradição de intérpretes shakespearianos no Brasil - que torna aquela uma estréia absoluta, um salto sem rede. ${ }^{24}$

\section{Álibi para um adeus}

O intuito de impostar o repertório da nova Cia. Tônia-CeliAutran no eixo principal dos clássicos universais - a Shakespeare seguem, no programa, Goldoni, Sartre e Pirandello - é movido pela missão de recolher a herança dos grandes atores de tradição européia ("olhar para trás, olhar para trás: montar o repertório de Salvini, de Sarah Bernhardt" ${ }^{25}$ ). Por outro lado, o estímulo à formação de diretores e autores nacionais atende ao imperativo (ditado por pressão sociocultural contemporânea e adquirido no programa da nova companhia, redigido por Celi) de focalizar temáticas representativas da 'realidade da nação'. No entanto, propondo sua solução para a crise de público, Celi faz questão de indicar como indispensável ao teatro não a mensagem, mas, sim, o valor estético do espetáculo - sua capacidade de "transmitir emoções em larga escala" por meio

22. Em 1954, ao jornalista C.M. de Araújo, Celi confessa ser sua máxima aspiração a direção de Ricardo II; de modo que, deparando com o fantasma de Molière, reagiria - Mais um francês? Então tá...

23. Segundo relata Alberto Cavalcanti, diretor artístico da Vera Cruz, em 1951 Celi recusa-se a dirigir Escravo da noite (a biografia de Noel Rosa órfã de diretor depois das demissões de Jacobbi) antes de ter montado Noite de reis no TBC.

24. A questão é reproposta por Celi no Correio da Manhã, 6/5/1956, /Teatro/, Sessenta dias de Shakespeare.

25. Tônia Carrero, in Lopes \& Saadi. 
do aparelho expressivo que é o ator em cena. Esse, assim como um craque de futebol exaltando sua torcida, deve assumir sua missão de instrumento de emoções: "deve saber doar ao texto uma quarta dimensão, deve revelá-lo em seu substrato humano, deve fazê-lo chegar ao público intensa e emotivamente, deve fazer com que o conflito de um personagem seja o conflito do público" (in Almeida, 1987: 32). Assim, a asserção paradigmática da soberania do texto - qualquer que seja sua mensagem - é reafirmada por Celi, enquanto suaviza a asserção do exercício monopolista da direção (palavra, por sinal, prudentemente substituida por 'encenação'), sendo declarada, ao contrário, a intenção de "conscientizar" os atores e de formar novos 'encenadores'. Emancipar o teatro brasileiro dos mestres estrangeiros torna-se (paradoxalmente) missão de Celi nessa fase, que o vê mais 'brasileiro' desde a seleção do repertório (com quatro textos nacionais, porque "esse é o caminho e vocês abram os olhos", cita-o Tônia) até a adoção da vocação mambembeira que o faz viajar ao longo de duas temporadas no interior do país para devolver a arte à realidade, à humanidade simples, ao público virgem. ${ }^{26}$ Neste contexto descentrado reafirma sua fé na dramaturgia como mundo das essências imutáveis e das emoções universais, comunicáveis na confluência das latitudes em que a humanidade comunga seus dramas além das fronteiras (assim, Pirandello interessa a qualquer província, Checov, a qualquer sociedade rural). A missão do diretor, ainda, é a de negar-se à imitação superficial da realidade, em busca do que é mais profundamente humano - "esquecer num primeiro momento a nacionalidade da peça e estudar as condições, os defeitos e as virtudes dos homens em determinada condição social. Uma

26. De 'missão' fala Celi na cena de Álibi, em que, enquanto representa para o humilde povo de uma aldeia mineira o papel do pai em Seis personagens, recebe telegrama de Gassmann anunciando o boom na Itália: "Aqui todo mundo tem mansões, carros de luxo, mulheres. Imbecil, o que você está fazendo aí? Volte antes que seja tarde demais. Me surpreendo com a carta na mão [...] Observo o público: gente simples, que veio à praça ver Pirandello do mesmo jeito que assiste à banda passar. Crianças, velhos, jovens, mulheres e mendigos me olham com atenção e espanto. Um grande orgulho me invade [...] sinto que estou cumprindo uma missão. Que essas pessoas precisam de mim, neste momento. Amasso a carta de Vittorio e a jogo fora". 
vez conseguida essa sinceridade universal, nos ocorre de recorrer à observação cotidiana, ao estudo mais histórico, adaptando algumas especialidades exclusivamente brasileiras. Ao nosso ver, poder prescindir da nacionalidade na interpretação de uma peça é conferir a ela o maior elogio possível: é ter encontrado nela algo que poderia passar aos confins, algo que, além de ser representativo de certa sociedade do Rio ou de São Paulo, é um grito de revolta compreensível em qualquer país." ${ }^{27}$ No entanto, o íntimo descompromisso de Celi com o assunto da 'brasilidade', traduzindo-se em expressões de tédio diante da crescente coação à adaptação local dos textos, ${ }^{28}$ contribui no final da década de 1950 para desarticular seu discurso teórico da prática imposta pela eficiência teatral; e provoca, nessa etapa da história brasileira, marcada por reinvindicações sociais, o irreversível esvaziamento de suas relações com a geração emergente. Essa, cuja tarefa conjuntural será a de tachar os diretores italianos de formalismo ${ }^{29}$ e de incapacidade, por serem estrangeiros, de 'entender o Brasil', é a geração retratada por Celi no grupo de jovens cineastas (em Álibi) que, concordes e apostando na "força nova" do país, lembram-lhe, "talvez com carinho" que está ali "somente de passagem" ${ }^{30}$

Em clima de finalização, por um lado Celi acerta os ponteiros de seu idealismo programático e, revelando sinais de cansaço, remonta com o CTCA seus mais memoráveis espetáculos no TBC (Entre quatro paredes, 1956; Seis personagens, 1959), evitando o debate contemporâneo, ao passo que obedece à pressão na bilheteria. Por outro lado, parece buscar um álibi no parcial falimento de sua missão, desistindo aos poucos do programa inicial da companhia e, ao mesmo tempo, afirmando com veia polêmica seu papel de

27. Programa de Santa Marta Fabril S/A, 1955, TBC-SP.

28. Já na Itália, montando Pinter, reagirá aos atores que pretendem "trazer o texto a si", pois "adaptar é uma forma possível, porém não a minha" - explica ao jornalista que o entrevista para o Jornal do Brasil, cad. B, 19/6/1978

29. "Celi me fazia descobrir as qualidades dramáticas de um texto estrangeiro [...] mas não buscava o sentido brasileiro do teatro", lembra, para todos os que nos anos 60 partilharam dessa opinião, Claudio Correa e Castro (entrevistado por Lopes, 8.6.81).

30. Entre eles, representando a si mesmos, Vianninha e Cecil Thiré. 
'antagonista' - enquanto estrangeiro e mais velho - à produção politizada e nacionalista dos jovens. ${ }^{31}$ Sintoma da decepção talvez seja a virada pessimista que afunda a realização afirmativa do artista (a criação) numa "eterna e indestrutível ilusão": nessa fase Celi, em vez de buscar no teatro um espaço e o tom para a "discussão pública" (como no Pirandello de 51), encontra nele "o único consolo de poder [...] transmitir o caos à posteridade" (como no mesmo Pirandello, remontado em 5932). Compreensível, a 'raiva' (como a evoca em Álibi) de renovador que resiste a um destino de acomodado lhe suscita considerações por demais amargas, movidas pela deprimida sensação de estar no fim da linha de sua aventura americana - considerações que, embora não fazendo jus ao extraordinário percurso brasileiro de Celi, justificam a partida pelo esgotamento da missão: "Passada a curiosidade intelectual das elites, o público está de mãos vazias, porque tal repertório internacional não correspondia às condições brasileiras e deixou de interessar-se por não sentir nesse repertório uma identificação mais profunda, capaz de lhe manter um interesse permanente." 33

O confuso sentimento de impotência e exclusão arrisca cortar o prazer da aventura americana - de ter vivido, amado e sofrido por anos imprevisivelmente longos, tendo amadurecido naquele país "quente e hospitaleiro, desde o primeiro dia" (evoca em Álibi). Azul e ensolarada, com seus cartões postais explorados pela câmera ao ritmo frenético dos atabaques e sua proverbial exuberância floral e humana, é a vista do Rio de Janeiro que, pelo olhar deste homem entre dois mundos, resume o sabor festivo do país e justifica, em Álibi, a longa paixão por uma terra "eternamente jovem" em que ele, estrangeiro, começa a sentir-se velho. A experiência revela-se esgotada, especialmente em razão da eterna juventude deste Brasil impávido e incapaz de memória, "cuja força consiste no fato de que

31. "Sempre desconfiei das temáticas imediatas nas obras dramáticas. Considero passageiro o entusiasmo para certas formas de drama-documento, pois o lance polêmico mostra o vício de uma extrema contingência [...] sem bases morais nem existenciais", no programa do CTCA, cit., in Almeida, 1987: 32.

32. Celi, programa de Seis personagens, CTCA-RJ, Teatro Mesbla, 1959

33. Celi, entrevista com Leo Victor, julho de 1961, Jornal do Brasil, in Almeida, 1987: 76 
muitos morrem jovens". Assim, mais forte do que a saudade da terra exótica, o desejo de coerência desemboca para Celi em carência de pertencimento e em saudade de sua geração: "Faz tempo que não escrevo" em Álibi imagina responder a Vittorio Gassmann, anunciando seu regresso à Itália "Não sei mais nada de vocês. Há anos vocês me escreviam que deveria voltar. Nunca respondi. Aqui as coisas mudaram. Me sinto vazio. Dei tudo o que tinha que dar e tive que fazer tudo sozinho. Foi muito cansativo. Não agüento mais. Sinto que estou afundando. Sou preguiçoso, não leio mais. Faço coisas medíocres para sobreviver. Me sobrou apenas uma certa vitalidade animalesca, quase corrupta... tenho medo. Vejo os filmes de vocês e me parecem extraordinárias as suas vitalidade e franqueza, sua coragem. Creio na sua coerência. Quero voltar a ser como vocês..."

\section{Bibliografia}

ALMEIDA, Ines Barroso. Panorama visto do Rio: Cia. Tônia-CeliAutran. Rio de Janeiro: MinC, Inacen, 1987.

CATÁLOGO da Mostra 'Vera Cruz'. Centro Cultural Banco do Brasil, Rio de Janeiro, 14.2 a 2.3.1997.

DEPOIMENTOS nn. I, II, III, IV, V, VI. Rio de Janeiro, MEC-DAC. Serviço Nacional de Teatro.

DIONYSOS. Revista de teatro. nn. 1, 22, 24, 25, 26. Rio de Janeiro: MinC - Fundacen.

FERNANDES, Nancy e VARGAS, Maria Theresa. Uma atriz: Cacilda Becker. São Paulo: Perspectiva, 1983.

GALVÃO, Maria Rita. Burguesia e cinema. O caso Vera Cruz. Rio de Janeiro: Civilização Brásileira, 1981.

GAMBETTI, Giacomo. Vittorio Gassman. Bologna:Cappelli, 1962. GUZIK, Alberto. Autran, um homem no palco. São Paulo: Boitempo, 1998.

TBC: crônica de um sonho, 1948-1964. São Paulo: Perspectiva, 1986. 
LEITE LOPES, Angela e SAADI, Fátima. 'A influência dos diretores estrangeiros no teatro brasileiro', 1980-81.

LERNER, Júlio e outros. A aventura do teatro paulista. Programa da TV Cultura, Canal 2, set-ott. 1981

MELDOLESI, Claudio. Fondamenti del teatro italiano. La generazione dei registi. Firenze: Sansoni, 1984.

RABETTI, Maria de Lourdes Giannella (Beti Rabetti). Contribuição para o estudo do 'moderno' teatro brasileiro: a presença italiana. São Paulo, 1989. Tese de Doutoramento em Ciências Humanas - USP.

VANNUCCI, Alessandra. Ruggero Jacobbi ou da transição necessária. Estratégias da modernização teatral no Brasil entre tradição cômica e mercado cultural (década de 1950). Rio de Janeiro, 2000. Tese de Mestrado em Teatro - UniRio. 